\title{
Akış Sitometrisinin (Flow Cytometry) Sperma Kalite Analizlerinde Kullanımı
}

\author{
Fırat KORKMAZ ${ }^{1 a \otimes}$, Beste ÇiL ${ }^{2 b}$ \\ 1. Uluslararası Hayvancılık Araştırma ve Eğitim Merkezi Müdürlüğü, Ankara, TÜRKiYE. \\ 2. Ankara Üniversitesi, Veteriner Fakültesi, Dölerme ve Suni Tohumlama Anabilim Dalı, Ankara, TÜRKiYE.
} ORCID: 0000-0002-9600-908Xa, 0000-0003-2822-1625

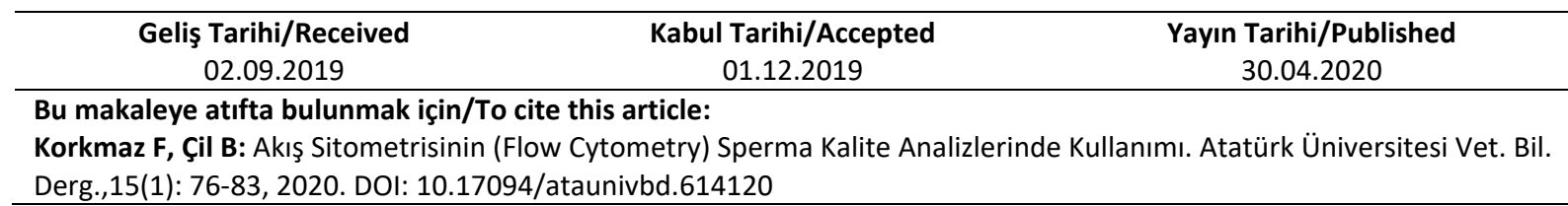

Öz: Spermanın kalite analizleri, infertilitenin tanımlanmasında ve yardımcı üreme teknikleri yönünden günümüz bilim dünyasında değer kazanmaya başlamıştır. Bu analizlerde tercih edilen yöntemlerin en gelişmişlerinden biri olan akış sitometrisi, akış halindeki bir süspansiyon içindeki çeşitli boyut ve yapıdaki hücre, nükleus ve benzeri hücre komponentleri, kromozomal yapılar ve çeşitli partikülleri de kapsayan taneciklerin, lazer ve özelleştirilmiş dedektörler yardımıyla nitelik ve nicelik özelliklerinin ölçülmesine dayanan bir yöntemdir. Bu amaçla, florokrom moleküllerle boyanmış örneklere ait partiküllerin tek sıralı hale getirilmesinin ardından optik sistemden saçılan lazer ışınına maruz kalmakta, geri dönen ışınlar ise toplanarak elektronik sinyallere dönüştürülmektedir. Elektronik sinyaller ise yazılımlar ile değerlendirilmektedir. Akış sitometrisinin, geniş kullanım yelpazesi içerisinden, gelişen infertilite teşhis metodları ve yardımcı üreme teknikleri sayesinde ilk olarak beşeri androloji laboratuvarlarında, hemen ardından ise veteriner androloji laboratuvarlarında, spermatozoanın konsantrasyonu; plazma membran ve akrozom bütünlüğü; apoptosis; mitokondriyal membran potansiyeli; kapasitasyon; oksidatif stres; lipid peroksidasyonu; DNA bütünlüğü ve cinsiyetin belirlenmesi vb. amaçlar ile kullanılmaya başlanmıştır. Bu derlemede akış sitometrisi ve analizlerinin sperma kalitesini belirlemedeki rolü ve önemi açıklanarak ilgili sperm kalite parametrelerinin ölçümünde kullanılan protokoller hakkında detaylı bilgilendirme sağlanması hedeflenmiştir.

Anahtar Kelimeler: Akış Sitometrisi, Cinsiyeti Belirlenmiş Sperma, Sperma Analizi, Suni Tohumlama, Veteriner Androloji.

\section{The Use of Flow Cytometry in Semen Quality Analyses}

Abstract: Quality analysis of semen has started to gain value in the recent scientific world in terms of defining infertility and assisted reproductive techniques. Flow cytometry, the most advanced method of choice in these analyzes, is a method based on measuring the quality and quantity of particles including cells, nucleus, chromosomal structures and various particles with its sizes and structures in a flowing suspension by means of lasers and detectors. For this purpose, the particles that are stained with fluorochrome molecules are exposed to the laser beam scattered from the optical system after being unified, and the returning rays are collected and converted into electronic signals. Electronic signals are evaluated with softwares. Within a wide range of uses, i.e. the concentration of spermatozoa; plasma membrane and acrosome integrity; apoptosis; mitochondrial membrane potential, capacitation status; oxidative stress; lipid peroxidation; DNA integrity and gender determination purposes etc., it has been used as infertility diagnostic methods and assisted reproductive techniques which have been developed, firstly in human andrology laboratories and then in veterinary andrology laboratories. The aim of this review is to explain the role and importance of flow cytometry and in determining sperm quality and to provide detailed information about the relevant protocols.

Keywords: Artificial Insemination, Flow Cytometry, Semen Analyses, Sexed Semen, Veterinary Andrology. 
GiRiş

M ${ }_{\text {Leeuwenhoek'un (1) } 1677 \text { yılında 'animalculus' }}^{\text {ikroskobun mucidi olan Antoni van }}$ olarak tanımladığı spermatozoonların keşfiyle birlikte sperma kalite analizlerinin de ilk ve en önemli adımı atılmıştır. Sadece varlığı ve hareket modelleri belirlenen spermatozoonun, yavruyu kendi başına oluşturabileceğine inanılan organizmacık ya da bir parazit gibi düşünülen spermatik kurtçuk tanımlarından sıyrılması ise dişi gamet hücresinin oosit- keşfi, fertilizasyonun ve gametogenezisin anlaşılması ile 1900'lü yılların başlarında gerçekleşmiştir (2). Böylece sperma kalite analizleri de ilk olarak infertilitenin tanımlanmasında ve ardından yardımcı üreme teknikleri yönünden bilim dünyasında değer kazanmaya başlamıştır. İzleyen yıllarda, ejakülat içerisindeki spermatozoon sayısının belirlenmesi (3), sperm motilite tayini (4-6), sperm anomali ve morfolojisi $(7,8)$, Bilgisayar destekli sperm analizi (CASA) gibi yöntemler birçok androloji laboratuvarının standardına girerek kullanılmaya başlanmıştır (9).

1970'li yılların sonunda ise ilk kez akış sitometrisi ve sperm tanımlarının birlikte anıldığı çalışma van Dilla ve ark. (10) tarafından yayınlanmıştır. Sperma kalite analizlerine yönelik, floresan temelli, birkaç saniye içinde binlerce hücrenin monitarizasyonunu sağlayan bu yöntem 2000'li yıllarla birlikte ivme kazanarak, spermatozoa canlılık, mitokondriyal membran potansiyeli, lipid peroksidasyon, oksidatif stres, DNA analizi gibi birçok kalite parametre analizinin yanı sıra, cinsiyet seçimini de olanaklı hale getiren bir yöntem olarak geliştirilmiştir.

Akış sitometrisi, akış halindeki bir süspansiyon içindeki çeşitli boyut ve yapıdaki hücre, nükleus, kromozomal yapılar ve çeşitli partikülleri de kapsayan taneciklerin, lazer ve dedektörler yardımıyla nitelik ve nicelik özelliklerinin ölçülmesine dayanan bir yöntemdir. Üç bileşenden oluşan akış sitometrisinde; ölçülecek partikülleri lazer önüne taşıyan akışkanlar sistemi, ölçüm yapan lazerleri içeren ve partiküllerden dönen sinyalleri toplayan dedektörleri barındıran optik sistem, bu optik sinyalleri elektronik sinyallere çeviren ve değerlendirilebilir hale getiren elektronik sistemler bulunur.

Çalışma prensibi basitçe; florokrom moleküllerle (Tablo 1.) boyanmış örneklere ait partiküllerin, hidrodinamik ya da akustik odaklanma ile tek sıralı hale getirilişi, optik sistemden lazer ışın saçılması, partiküllerin ışına maruz bırakılması, dönen ışının toplanması ve toplanan verilerin elektronik sinyallere dönüştürülerek değerlendirilmesi olarak tanımlanmaktadır. Tüm bu süreç bir saniye içerisinde binlerce partiküle uygulanabilir ve bu partiküllerin sayısı 'events- kayıt' olarak tanımlanmaktadır. Tekli ya da çoğul sonuçlar genellikle bir histogram ya da dot plot aracılığıyla yapılacak seçim işlemi ile ölçüm yapılan popülasyona göre yüzdesel ya da rakamsal olarak elde edilmekte ve değerlendirilmektedir.

Tablo 1. Sperma muayenesinde kullanılan çeşitli florokromlar (11).

Table 1. The various fluorochromes used in semen examination (11).

\begin{tabular}{|c|c|c|c|c|c|c|c|}
\hline $\begin{array}{l}\text { Membran } \\
\text { Bütünlüğü }\end{array}$ & $\begin{array}{l}\text { Membran } \\
\text { Stabilitesi }\end{array}$ & $\begin{array}{l}\text { Plazma Membran } \\
\text { Ve Akrozom Bütünlüği }\end{array}$ & $\begin{array}{l}\text { Mitokondriyal } \\
\text { Bütünlük }\end{array}$ & $\begin{array}{l}\text { Oksidatif } \\
\text { Stres }\end{array}$ & $\begin{array}{l}\text { Lipid } \\
\text { Peroksidasyon }\end{array}$ & $\begin{array}{l}\text { Kromatin/DNA } \\
\text { Bütünlüğü }\end{array}$ & Apoptosis \\
\hline CFDA & Mero-540 & $\begin{array}{l}\text { SYBR-14/PE- } \\
\text { PNA/PI }\end{array}$ & Rhodamine & DCFDA & BODIPY C11 & TUNEL & $\begin{array}{l}\text { Annexin } \\
\text { V }\end{array}$ \\
\hline $\begin{array}{l}\text { SYBR- } \\
14 / P I\end{array}$ & Yo-PRO-1 & $\begin{array}{l}\text { FITC-PNA/PSA- } \\
\text { PI }\end{array}$ & JC-1 & MITOSOX & & COMET & \\
\hline Etdh & SNARF-1 & Ca iyonoforları & MitoTracker & $\begin{array}{l}\text { CellROX } \\
\text { Deep Red, } \\
\text { Green, } \\
\text { Orange }\end{array}$ & & SCSA & \\
\hline $\begin{array}{l}\text { CellROX } \\
\text { Deep } \\
\text { Green }\end{array}$ & & & & DHE & & & \\
\hline
\end{tabular}




\section{BIYOMEDIKAL ALANDA KULLANIMI}

Akış sitometrisi tekniği biyomedikal alanda özel laboratuvarlar ve hastanelerde kendisine önemli bir yer edinmiştir. Kanser tanı ve aşamalandırılması (12), HIV prognozunun tayini (13), çeşitli kan hastalıkları (lenfoma, lösemi gibi) (14,15), intrasellüler komponentlerin değişimi (Kalsiyum, lipid vb.) (16), DNA bütünlüğü (17) ya da ek cihazlar ile sorting (ayırma) sayesinde hücrelerin birbirinden ayrılması (cinsiyet seçimi gibi) (18-19) gibi durumlarda dünyada sıklıkla kullanılmaktadır.

\section{VETERINER ANDROLOJIDE KULLANIMI VE SPERMA KALITE MUAYENESI TESTLERI}

Geniş kullanım yelpazesi içerisinde, gelişen infertilite teşhis metodları ve yardımcı üreme teknikleri sayesinde ilk olarak beşeri androloji laboratuvarlarında ardından da veteriner androloji laboratuvarlarında kullanılmaya başlanmıştır (20). Bu bağlamda veteriner androloji alanında akış sitometrisinin kullanım alanları;

\subsection{Konsantrasyon Ve Spermatozoa Sayımı (Spermatozoa Konsantrasyonu)}

Spermatozoa konsantrasyonunun belirlenmesi gerek dondurma prosedürleri gerekse in vitro fertilizasyon (IVF) uygulamaları açısından önem taşımaktadır. Bu amaçla yapılacak ölçümlerde, hemositometre, spektrofotometre ya da CASA yöntemlerine alternatif olarak akış sitometrisi de kullanılabilir bir yöntemdir. Diğer metotlardan farklı olarak, 'beads' denilen taneciklerin örneğe eklenmesi ve saydırılması şeklinde ya da bir kalite analizine (özellikle canlılık (SYBR-14/PI)) ek olarak bu işlem gerçekleştirilebilir. Bu amaçla genellikle, türe bağlı olmakla birlikte boğa sperması için, dilüe edilen ejakülat (1:100- 1:250) ya da dondurulmuş çözdürülmüş $60 \times 10^{6}$ sperma (1:20) SYBR-14 ve Propidium iodide (PI) boyama yöntemleriyle boyanarak belirli bir hacim ayarlanarak analize tabi tutulur ve Forward Scatter (FS)/Side Scatter (SS) alanlarından popülasyonun belirlenmesi ile toplanacak sayım verisi, önceden bilinen hacim için konsantrasyon verisi olarak değerlendirilir $(21,22)$. Ancak bu yöntemin, hızı olmasının yanısıra canlılık oranına ek olarak alınması olumlu olarak değerlendirilse de sperma sulandırıcılarında bulunan farklı partiküllerden ve az hacimli örneklerde yapılan pipetleme uygulaması hatalarından etkileneceği unutulmamalıdır.

\subsection{Spermatozoonun Plazma Membran Ve Akrozom Bütünlüğü (PMAl= Plazma Membranı Ve Akrozomu Sağlam Spermatozoa)}

Sözcük anlamı 'yaşayabilirlik' olarak tanımlanan viyabilite içinde de değerlendirilen plazma membranı veya akrozom bütünlüğü fertilite açısından da önemli belirteçlerden bir tanesidir. Spermatozoonun plazma membran ve akrozom bütünlüğünü birlikte değerlendiren bu analiz de androloji laboratuvarlarının birçoğunun kullanmakta olduğu floresan boyaların akış sitometrisi yöntemine adapte edilmesi sonucu hızlı ve güvenilir sonuçlar elde edilebilmektedir. Bu amaçla yaygın olarak, SYBR-14, Propidium iodide (PI), FITC-PNA, FITC-PSA, Yo-Pro-1, 7-AAD, rhodamine 123 , carboxyfluorescein diacetate gibi floresan boyalar ya da PI ile kombinasyonları kullanılmaktadır (20). Teknik, genellikle PI ile kombinasyonların membrandan geçebilen (örn. PI) ya da geçemeyen DNA'ya bağlanabilen (örn. SYBR14) florokromların saptanması üzerine kuruludur. Bu amaçla örnekler SYBR-14 ve PI ile laboratuvarların kendine ait protokolleri kapsamında boyanarak (23) $488 \mathrm{~nm}$ lik argon lazer ve $515 \mathrm{~nm}-545 \mathrm{~nm}$ (SYBR), 561 nm-583 nm emisyon filtreleri ile ölçümleri yapılır. Boğa spermasında PMAI'nin belirlenmesinde, çok yaygın olarak kullanılan SYBR-14/PI kombinasyonunun Nagy ve ark. (24) yapmış oldukları çalışma ile tekrarlandığında verdiği doğruluk ve dondurma aşamasında eklenen yumurta sarısından dolayı verdiği hata sebebiyle yerini fluorescein isothiocyanate (FITC)-conjugated PNA ve PI kombinasyonuna bırakması önerilmektedir. Böylece, FITC-PNA ile akrozom bütünlüğü değerlendirilirken, PI ile plazma membran bütünlüğü ile ilgili veri debrisden olabildiğince arındırılarak elde edilebilir. Bu amaçla, $5 \mu$ I FITC-PNA (100 $\mu \mathrm{g} / \mathrm{ml})$ ve $3 \mu \mathrm{l} \mathrm{PI} \mathrm{(2.99}$ 
$\mathrm{mM}), 492 \mu \mathrm{l}$ dilüe sperma solüsyonuna aktarılarak boyama yapılır (25).

\subsection{Apoptozis}

Apoptozis, kromatin agregasyonu, sitoplazmik ve nükleer defektleri de içeren programlı hücre ölümünü tanımlayan terimdir. Hücre ölümünün (Apoptozis), infertilite ile arasındaki bağlantıdan dolayı akış sitometrisi ile spermatozoa apoptozisin belirlenmesi hızlı ve güvenilir bir metod olarak karşımıza çıkmaktadır. Bu amaçla, hücre lipid membranının iç kısmında bulunan phosphatidylserine'lere afinitesi olan Annexin $\mathrm{V}$ en sık kullanılan florokrom olarak karşımıza çıkmaktadır. FITC konjuge hali ise, daha hassas olması sebebiyle ticari olarak da bulunmakta olan probun boğa sperması için kullanımı, ticari kitler de değişmekle birlikte, PI ile olmaktadır (26).

\subsection{Spermatozoanın Mitokondriyal Membran Potansiyeli}

Mitokondriyal membran potansiyeli, spermatozoon mitokondriyasının oksidatif fosforilasyon yoluyla ATP üretmesi ve kapasitasyon ile ilgili bir parametre olarak değerlendirilmektedir. Düşük mitokondriyal membran potansiyeli, spermatozoa anomalisine ya da dondurma çözdürme sırasındaki kriyo hasara bağlı olarak ortaya çıkabilmektedir. Bu sebeple mitokondriyal membran potansiyelinin belirlenmesi canlılık testleriyle birlikte önem taşımaktadır. Bu amaçla, 5,5' , 6,6'-tetrachloro1,1',3,3'-tetraethyl-benzimi-dazolyl-carbocyanine iodi de (JC-1), rhodamine 123 ve MitoTracker (MITO) sıklıkla kullanılan florokromlardır. JC-1, spermatozoon mitokondriyel membran potansiyelinin belirlenmesinde sık kullanılan prob olarak karşımıza çıkmaktadır. Düşük membran potansiyelinde; yeşil, yüksek olduğu durumlarda ise turuncu renkli ışıma veren bir florokrom olarak çalışmaktadır. Farklı protokoller $(25,27)$ ile yapılan boyama sonucu $488 \mathrm{~nm}$ Argon lazer ve 535 nm, 595 $\mathrm{nm}$ emisyon filtreleri yardımıyla ölçüm yapılır. Bu amaçla, $10 \mu \mathrm{lJC}-1$ (0.153 mM) ve $3 \mu \mathrm{lPI}(2.99 \mathrm{mM})$,
$487 \mu \mathrm{l}$ dilüe sperm solüsyonuna aktarılarak boyama yapılır (25). Elde edilen veri, düşük ve yüksek membran potansiyeli olarak iki popülasyon halinde değerlendirilir.

\subsection{Kapasitasyon}

Spermatozoa kapasitasyon seviyesinin ölçümü, spermatozoa da şekillenen kalsiyum (Ca) değişimlerinin florokrom özellik gösteren bir antibiyotik olan chlortetracycline (CTC) ile gerçekleştirilmektedir. CTC'nin hücre membranını hücreiçi maddelerden olan $\mathrm{Ca}$ geçirgenliğini arttırması sonucunda, serbest Ca'un hücre içine girişiyle CTC floresan özellik göstermekte bu da akış sitometrisi ile tespit edilerek, bir fertilizasyon öngörüsü olarak kapasitasyon seviyesi belirlenmektedir (28). Yine hücre içi Ca seviyesinin belirlenebilmesi için Fluo-3, ya da daha yeni bir prob olan Fluo-4 AM kullanılabilmektedir.

\subsection{Spermatozoanın Oksidatif Stresinin Belirlenmesi \\ Oksidatif stres, reaktif oksijen türlerinin (ROS)} oluşumu karşısında, spermanın kendi antioksidan savunma sistemlerinin yetersiz kalması ve sonucunda ortaya çıkan DNA bütünlüğünün bozulması, membran lipid yapısının defekti ve fertilitenin düşmesi ile gözlemlenebilen bir durumdur. Spermanın dondurulması ve çözdürülmesi işlemleri oksidatif stres oluşumunda büyük rol oynamaktadır (25). Bu nedenle, sperm oksidatif stres parametrelerinin ölçülmesi, dondurma çözdürme işlemlerine dayanıklılık açısından önem taşımaktadır. Oksidatif stresin akış sitometrisiyle belirlenmesinde, 5-(ve-6)-carboxy-2',7'-dichlorodihydrofluoresence indiacetate (DCFDA) sıkça kullanılan bir florokromdur. 5-(ve-6)-karboksi-2', 7'-diklorodihidro floresan'ın diasetat formu olan bu florokrom, hidroksil, süperoksid anyon, nitrojen dioksit radikalleri karbonat anyon radikalleri ve hidrojen peroksit tarafından yeşil floresans veren DCFH e çevrilir (29). Bu amaçla, $5 \mu$ DCFH-DA (10 mM) ve 3 $\mu \mathrm{l}$ PI (2.99 mM), $492 \mu$ l dilüe sperm solüsyonuna 
aktarılarak boyama yapılır (16). Bunun dışında yine, DHE, MitoSOX, DAF2-DA, CellROX Deep Red, CellROX Orange (30) oksidatif stres ölçümünde kullanılan florokromlardır. Bu metoda da yine bir canlı/ölü hücre ayrımı yapan florokrom eklenmesi (örn. PI) ölü spermatozoonların analiz dışına alınması ile daha doğru sonuç vermesini sağlayacaktır.

\subsection{Spermatozoanın Lipid Peroksidasyonu}

Çoklu doymamış yağ asitlerince zengin bir yapıya sahip plazma membranı içeren spermatozoonlara sahip türlerde oksidatif stres, ROS ile reaksiyona giren bu yağ asitlerinin yapısının bozulmasına ve bu sebeple membran yapılarının bozulup, spermatozoonun işlev kaybına sebep olmaktadır. Lipid Peroksidasyonun (LPO) ortaya konulmasında, yağ asidi analoğu C11BODIPY581/591 oldukça sık kullanılan bir LPO tespit florokromudur (31). Bozulmamış membran yapısında kırmızı, perokside olmuş membranda ise yeşil (520 $\mathrm{nm}$ ) ışıma veren florokrom yine $\mathrm{PI}$ ile birlikte kullanılmaktadır. Bu amaçla $5 \mu$ BODIPY C11 (5mM) ve $3 \mu \mathrm{PI}$ (2.99 mM), $492 \mu$ l dilüe sperm solüsyonuna aktarılarak boyama yapılır (16).

\subsection{Spermatozoonun DNA Bütünlüğü}

Fertilizasyonun temeli olan genetik materyallerin birleşimi aşamasında spermatozoon DNA'sının paketleme hataları, DNA metilasyonları, histon katlanmaları; herediter olabildiği gibi, oksidatif strese bağlı olarak, çeşitli toksik etkiler altında ya da sperma kriyoprezervasyonu aşamasında ortaya çıkabilmektedir (25). Bu sebeple, fertilizasyon başarısı ve erken embriyonik yaşamın önemli bir kriteri olan DNA bütünlüğü sperma kalite değerlendirmesinde önem taşımaktadır. DNA bütünlüğü, akış sitometrisi ile terminal deoxynucleotidyl transferase dUTP nick end labeling (TUNEL) ya da sperm chromatin structure assay (SCSA) ile ortaya konulabilir $(17,32)$. TUNEL metodu, spermatozoon fiksasyonu ve ticari kitler ile birlikte $488 \mathrm{~nm}$ lazer ile değerlendirilmesine dayanmaktadır. Sperm kromatin yapı analizi (SCSA) ise spermatozoon nükleer kromatininin ISI denatürasyonuna dayanıklılığı ve acridine orange (AO) florokromunun çift iplikçikli DNA da yeşil, tek iplikçikli DNA da kırmızı ışıma vermesine dayalı bir yöntemdir (33). Sperma $\begin{array}{lllll}\text { örnekleri, } & \text { konsantrasyonları } & 2 & \text { x } & 10^{6}\end{array}$ spermatozoon $/ \mathrm{ml}$ olacak şekilde TNE buffer solüsyonu ile dilüe edilir. $200 \mu \mathrm{l}$ sperma örneği önce $400 \mu \mathrm{l}$ asit-deterjan solüsyonu (pH: $1.2,0.08-\mathrm{N} \mathrm{HCl}$, $0.15-\mathrm{M} \mathrm{NaCl}$, Ve $0.1 \%$ Triton $\mathrm{X}-100$ ) ile 30 saniye, ardından da fosfat sitrat tamponuna eklenmiş 1.2-mL (6 mg/L) saflaştırılmış AO (0.2-M Na2HPO4, 0.1-M sitrik asit,0.15-M NaCl, ve 1-mM EDTA, pH 6.0) ile boyanır. Örnekler, 3 dakikalık inkübasyonun ardından akış sitometrisi ile iki kez değerlendirilir (34).

\subsection{Spermatozoon Cinsiyetinin Belirlenmesi}

Suni tohumlama endüstrisinin yaygınlaşması ile birlikte, istenilen cinsiyette yavru eldesi yetiştiricilerin büyük ilgisini çekmiştir. Bu amaçla akış sitometrisi, percoll ve albumin gradient santrifüjü, yüzdürme, sefadeks kolonu, $\mathrm{H}-\mathrm{Y}$ antijeni metotları gibi birçok yöntem denenerek geliştirilmiştir (35). Bu yöntemlerin geliştirilmesindeki temel prensip $X$ ve $Y$ kromozomlarına sahip spermatozoonların taşıdığı DNA miktarı (36), hücrenin boyutu (37), yüzey yükü (38) veya yüzey antijenleri (39) bakımından farklı olmasıdır. En etkili ayrımın gerçekleştiği metot ise hala akış sitometrisi yöntemi olarak kabul edilmektedir (40). Ancak konvansiyonel tohumlamaya göre elde edilen düşük gebelik oranları, kullanılabilir sperma oranında düşüş, yüksek maliyet, eğitimli personel gereksinimi gibi çeşitli dezavantajları bu yöntemin uygulanabilirliğini sınırlamaktadır.

Sığırlarda X kromozomu taşıyan spermatozoon Y kromozomu taşıyana göre \%4 daha fazla DNA içermektedir ve bu farklılık sayesinde flow sitometri metoduyla \%90 oranında kesinlikle, işlenen spermatozoanın yaklaşık \%50'sinin ayrımı yapılabilmektedir. Kalan $\% 50$ ise cihaz tarafından cinsiyeti belirlenemediği için atık olarak ayrılmaktadır (41). Spermatozoanın DNA miktarının belirlenebilmesi için hücre membranından geçebilen 
ve DNA'ya bağlanan Hoeschst 33342 floresan boyaları kullanılmakta, boyanın yarattığı ışıma miktarı dedektör ile tespit edilmekte ve bilgisayar yardımı ile \%४'lük bu ışıma farkı analiz edilebilmektedir (40).

Kısaca, öncesinde ortalama 7 saat süresince modifiye edilmiş Tyrode's albumin laktat pirüvat (TALP) solüsyonu ile inkübe edilen spermaya Hoeschst 33342 boyası eklenerek yaklaşık $34^{\circ} \mathrm{C}$ sıcaklıkta 45 dakika inkübasyonu sağlanır. Ardından ayırma solüsyonu ile sulandırılan spermaya gıda boyası ve final konsantrasyon $\% 2$ olacak şekilde yumurta sarısı eklenir. Filtrasyonun ardından Tris bazlı sheath solüsyonu ile ayrım gerçekleştirilir (4143).

Cinsiyet ayrımı işleminin kalitesi sulandırma ve boyama prosedürlerini UV ışınlarına Akış Basıncına elektrostatik alan ve elektrik yüküne bağlı olarak değişkenlik gösterebilmektedir. Ayrıca sıcaklık, ozmolarite, $\mathrm{pH}$ ve kullanılan solüsyonların sterilitesi de işlemin başarısını etkileyebilmektedir $(44,45)$.

\section{SONUÇ}

Saha yönelimleri ve teknolojideki gelişmelere göre yenilenen laboratuvar teknikleri arasında kendisine önemli bir yer edinmiş akış sitometrisi metodu bu derlemeyle birlikte veteriner hekimliği androloji laboratuvarlarında kullanım yönüyle, çalışma prensibi ve temel boyama metotlarının teknik detaylarıyla değerlendirilmiştir. Tüm bunlara ek olarak, anlık zamanlarda yüksek ölçüm hızı, objektif olması ve fertiliteye ilişkin sonuçlar verebilmesi yönünden değerli bu metodun kısa ve uzun vadedeki gelişmeleri yakından takip edeceği ve veteriner androloji alanında öncül metotlardan biri olacağı öngörülmektedir.

\section{Çıkar Çatışması}

Yazarlar, çıkar çatışması olmadığını beyan eder.

\section{KAYNAKLAR}

1. Leeuwenhoek A., 1677. Observationes de Anthonu Lewenhoeck, de natis e semine genitali animalculis. Phil Trans Roy Soc, 12, 1040-1043.

2. Andrade-Rocha FT., 2017. On the origins of the semen analysis: A close relationship with the history of the reproductive medicine. J Hum Reprod Sci, 10, 242.

3. Lode A., 1891. Untersuchungen über die Zahlenund Regenerationsverhältnisse der Spermatozoiden bei Hund und Mensch. Pflug Arch Eur J Phy, 50, 278-292.

4. Martin E., Carnett JB., Levi JV., Pennington ME., 1902. The surgical treatment of sterility due to obstruction at the epididymis; together with a study of the morphology of human spermatozoa. Univ Pa Med Bull, 15, 2-15.

5. Detlefsen JA., 1914. Genetic studies on a cavy species cross. Carnegie Instit Wash, 205, 1-134.

6. Hühner M., 1921. Methods of examining for spermatozoa in the diagnosis and treatment of sterility. Int J Surg, 34, 91-100.

7. Zeleny C., Faust EC., 1915. Size dimorphism in the spermatozoa from single testes. J Exp Zool, 18, 187-240.

8. Williams WW., Savage A., 1925. Observations on the seminal micropathology of bulls. Cornell Vet, $15,353-375$

9. Amann RP., Waberski D., 2014. Computerassisted sperm analysis (CASA): capabilities and potential developments. Theriogenology, 81, 517.

10. van Dilla MA., Gledhill BL., Lake S., Dean PN., Gray JW., Kachel V., Göhde W., 1977. Measurement of mammalian sperm deoxyribonucleic acid by flow cytometry. Problems and approaches. J Histochem Cytochem, 25, 763-773.

11. Rodriguez-Martinez H., 2014. Semen evaluation and handling: emerging techniques and future development. In "Animal Andrology: Theories and Applications" Ed., PJ Chenoweth, 509-549. Reproduction Resources, USA

12. Barlogie B., Raber MN., Schumann J., Johnson TS., Drewinko B., Swartzendruber DE., Göhde W., Andreeff M., Freireich EJ., 1983. Flow cytometry in clinical cancer research. Cancer Res, 43, 3982- 
3997.

13. Hengel RL., Nicholson JK., 2001. An update on the use of flow cytometry in HIV infection and AIDS. Clin Lab Med, 21, 841-856.

14. Solly F., Angelot-Delettre F., Ticchioni M., Geneviève F., Rambaud H., Baseggio L., Plesa A., Debliquis A., Garnache-Ottou F., Roggy A., Campos L., Aanei C., Rosenthal-Allieri A., Georget M., Lachot S., Jacob M., Robillard N., Wuilleme S., Andre-Kerneis E., Cornet E., Salaun V., Bennami H., Lhoumeau A., Arnoulet C., Jacqmin H., Neyman N., Latger-Cannard V., Massin F., Lainey E., Le Garff-Tavernier M., Costopoulos M., Roussel M., Mayeur-Rousse C., Eischen A., Raggeneau V., Derrieux C., Maurer M., Asnafi V., Trinquand A., Brouzes C. and Lhermitte L. 2019. Standardization of Flow Cytometric Immunophenotyping for Hematological Malignancies: The FranceFlow Group Experience. Cytometry, 95, 1008-1018.

15. Dong HY., Kung JX., Bhardwaj V., McGill J., 2011. Flow cytometry rapidly identifies all acute promyelocytic leukemias with high specificity independent of underlying cytogenetic abnormalities, Am J Clin Pathol, 135, 76-84.

16. Korkmaz F., Malama E., Siuda M., Leiding C., Bollwein H., 2017. Effects of sodium pyruvate on viability, synthesis of reactive oxygen species, lipid peroxidation and DNA integrity of cryopreserved bovine sperm. Anim Reprod Sci, 185, 18-27.

17. Evenson DP., 2016. The Sperm Chromatin Structure Assay $\left(\mathrm{SCSA}^{\circledR}\right)$ and other sperm DNA fragmentation tests for evaluation of sperm nuclear DNA integrity as related to fertility. Anim Reprod Sci, 169, 56-75.

18. Ibrahim SF., van den Engh G., 2007. Flow cytometry and cell sorting. In "Cell Separation". Eds., A., Kumar, IY., Galaev B., Mattiasson 19-39. Springer, Berlin, Heidelberg.

19. Manzoor A., Patoo RA., Akram T., Shah AA., Nazir T., 2017. Sperm sexing and its utility in commercial cattle production: A review. Adv
Anim Vet Sci, 5, 293-298.

20. Petrunkina AM., Harrison RAP., 2011. Cytometric solutions in veterinary andrology: Developments, advantages, and limitations. Cytometry A, 79, 338-348.

21. Christensen P., Stenvang JP., Godfrey WL., 2004. A flow cytometric method for rapid determination of sperm concentration and viability in mammalian and avian semen. J Androl, 25, 255-264.

22. Yang H., Daly J., Tiersch TR., 2015. Determination of sperm concentration using flow cytometry with simultaneous analysis of sperm plasma membrane integrity in zebrafish Danio rerio. Cytometry, 89, 350-356.

23. de Lourdes Pereira M., Oliveira H., Fonseca HM., e Costa FG., Santos C., 2016. The Role of Cytometry for Male Fertility Assessment in Toxicology. In "Flow Cytometry: Select Topics". Eds. I., Schmid, 13-29, Intech Open.

24. Nagy S., Jansen J., Topper EK., Gadella BM., 2003. A triple-stain flow cytometric method to assess plasma-and acrosome-membrane integrity of cryopreserved bovine sperm immediately after thawing in presence of egg-yolk particles. Biol Reprod, 68, 1828-1835.

25. Gürler H., Malama E., Heppelmann M., Calisici O., Leiding C., Kastelic JP., Bollwein H., 2016. Effects of cryopreservation on sperm viability, synthesis of reactive oxygen species, and DNA damage of bovine sperm. Theriogenology, 86, 562-571.

26. Chaveiro A., Santos P., Da Silva FM., 2007. Assessment of sperm apoptosis in cryopreserved bull semen after swim-up treatment: a flow cytometric study. Reprod Domest Anim, 42, 1721.

27. Gliozzi TM., Turri F., Manes S., Cassinelli C., Pizzi F., 2017. The combination of kinetic and flow cytometric semen parameters as a tool to predict fertility in cryopreserved bull semen. Animal, 11, 1975-1982.

28. Kerns K., Zigo M., Drobnis EZ., Sutovsky M., Sutovsky P., 2018. Zinc ion flux during mammalian 
sperm capacitation. Nat Commun, 9, 2061.

29. Kalyanaraman B., Darley-Usmar V., Davies KJ., Dennery PA., Forman HJ., Grisham MB., 2012. Measuring reactive oxygen and nitrogen species with fluorescent probes: challenges and limitations. Free Radic Biol Med, 52, 1-6.

30. de Castro LS., de Assis PM., Siqueira AF., Hamilton TR., Mendes CM., Losano JD., Assumpçao ME., 2016. Sperm oxidative stress is detrimental to embryo development: a dose-dependent study model and a new and more sensitive oxidative status evaluation. Oxid Med Cell Longev, 8213071.

31. Ball BA., Vo AT., Baumber J., 2001. Generation of reactive oxygen species by equine spermatozoa. Am J Vet Res, 62, 508-515.

32. Sharma R., Masaki J., Agarwal A., 2013. Sperm DNA fragmentation analysis using the TUNEL assay. In "Spermatogenesis". Eds., DT., Carrell, KI., Aston, 279-295. Humana Press, Totowa, NJ.

33. Evenson D., 2017. Evaluation of sperm chromatin structure and DNA strand breaks is an important part of clinical male fertility assessment. Transl Androl Urol, 6, 495.

34. Malama E., Zeron Y., Janett F., Siuda M., Roth Z., Bollwein H., 2017. Use of computer-assisted sperm analysis and flow cytometry to detect seasonal variations of bovine semen quality. Theriogenology, 87, 79-90.

35. Gledhill BL., 1988. Gender preselection: Historical, technical, and ethical perspectives. In "Seminars in reproductive endocrinology". 385395. Thieme Medical Publishers, Inc.
36. Garner DL., Gledhill BL., Pinkel D., Lake S., Stephenson D., van Dilla MA., Johnson LA., 1983. Quantification of the $\mathrm{X}$-and $\mathrm{Y}$-chromosomebearing spermatozoa of domestic animals by flow cytometry. Biol Reprod, 28, 312-321.

37. Cui KH., Matthews CD., 1993. X larger than Y. Nature, 366, 117-118.

38. Kiddy CA., Hafs HD., 1971. Sex ratio at birthprospects for control; a symposium (591.16 K5). A Symposium. ASAS, Champaign, IL.

39. Bradley MP., 1989. Immunological sexing of mammalian semen: current status and future options. J Dairy Sci, 72, 3372-3380.

40. Seidel Jr GE., 2007. Overview of sexing sperm. Theriogenology, 68, 443-446.

41. Seidel Jr GE., Garner DL., 2002. Current status of sexing mammalian spermatozoa. Reproduction, 124, 733-743.

42. Schenk JL., Suh TK., Cran DG., Seidel Jr GE., 1999. Cryopreservation of flow-sorted bovine spermatozoa. Theriogenology, 52, 1375-1391.

43. Garner DL., Evans KM., Seidel GE., 2013. Sexsorting sperm using flow cytometry/cell sorting. In "Spermatogenesis". Eds., DT., Carrell, KI., Aston, 279-295. Humana Press, Totowa, NJ.

44. Suh TK., Schenk JL., 2003. Pressure during flow sorting of bull sperm affects post-thaw motility characteristics. Theriogenology, 59, 516.

45. Vishwanath RJ., Moreno F., 2018. Review: Semen sexing - current state of the art with emphasis on bovine species. Animal, 12, 85-96. 